\title{
An Evaluation of the Influence of Stock Abundance and Global Temperature Anomaly on Pacific Salmon Body Weight in the North Pacific Ocean
}

\author{
Alexander V. Bugaev ${ }^{1}$ and Vladimir I. Radchenko ${ }^{2}$ \\ ${ }^{1}$ Kamchatka Fishery and Oceanography Research Institute (KamchatNIRO), 18 Naberezhnaya Street, \\ Petropavlovsk-Kamchatsky 683000, Russia
}

${ }^{2}$ North Pacific Anadromous Fish Commission, Suite 502, 889 West Pender Street, Vancouver, BC V6C 3B2, Canada

Keywords: Pacific salmon, average body weight, stock abundance, global temperature anomaly

The objective of this study is an evaluation of the relationships between Pacific salmon stock abundance, water temperature anomalies, and Pacific salmon body weight to determine a main salmon growth driving factor during their marine phase. Relationships between Pacific salmon catch values (1961-2015) as a stock abundance index, the Northern Hemisphere Land and Sea Surface Temperature Anomaly Index (N.HEMI+dSST), and salmon body weight in commercial catches of the North Pacific countries (Table 1) were assessed using stepwise multiple regression analysis. The temperature anomaly index values are calculated in correspondence with the marine phase duration of Pacific salmon species: two-year averaging is used for pink and coho salmon, four-year averaging is used for chum, sockeye, and Chinook (Bugaev 2017).

Table 1. Long-term average body weight (kg) of Pacific salmon in commercial catches, 1961-2015.

\begin{tabular}{lccccc}
\hline \multicolumn{1}{c}{ Species } & Russia & Japan & USA (Alaska) & USA (WOC) & Canada \\
\hline Pink & $1.34(1.10-1.62)$ & $1.26(0.94-1.79)$ & $1.61(1.23-2.22)$ & $2.10(1.37-2.96)$ & $1.86(1.39-2.98)$ \\
Chum & $3.48(2.80-4.05)$ & $2.96(2.12-3.76)$ & $3.61(3.07-4.13)$ & $4.52(3.48-5.22)$ & $5.22(4.34-6.26)$ \\
Sockeye & $2.74(2.29-3.30)$ & $2.07(1.48-3.00)$ & $2.71(2.16-3.39)$ & $2.60(1.54-2.99)$ & $2.78(2.21-3.37)$ \\
Coho & $3.14(2.50-3.76)$ & $2.53(1.72-4.00)$ & $3.41(2.81-4.01)$ & $3.20(2.05-4.91)$ & $3.29(2.48-4.09)$ \\
Chinook & 8.20 & 4.87 & 7.83 & 6.17 & 6.82 \\
& $(4.70-11.01)$ & $(2.41-10.00)$ & $(5.52-9.26)$ & $(3.59-10.39)$ & $(5.41-9.12)$ \\
\hline
\end{tabular}

Pacific salmon catches by the NPAFC member countries reached historic high levels at the end of the first decade of the current century (see https://npafc.org/statistics/). Then, in odd years, overall commercial salmon fishery harvest fell about $20 \%$ from levels of 607 or 608 million fish to 507 million fish in 2015 . In even years, Pacific salmon catches follow the same trend with the historical record, in 2012, 464 million fish were caught and catches decreased to 389 million fish in 2014.

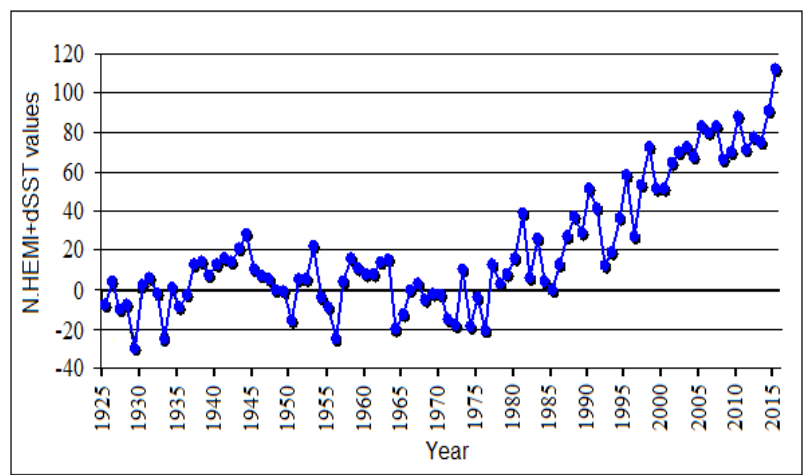

Fig. 1. Inter-annual dynamics of the Northern Hemisphere Land and Sea Surface Temperature Anomaly Index (N.HEMI+dSST), 1925-2015.

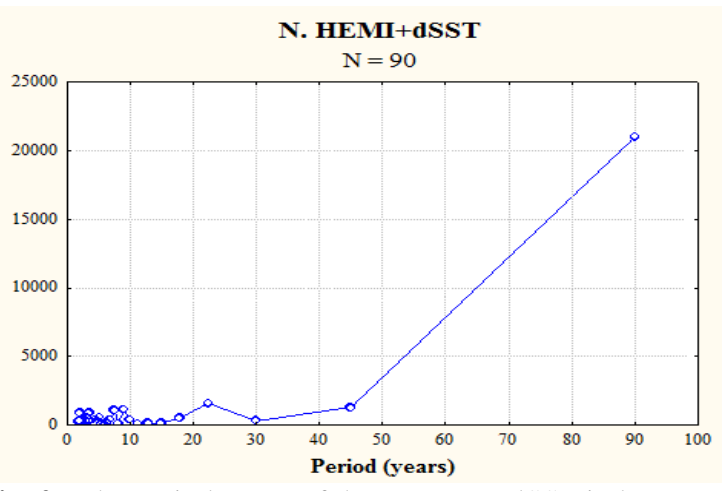

Fig. 2. The periodogram of the N.HEMI+dSST index obtained by means of Fourier spectral analysis, 1925-2015. 
Interannual dynamics of the N.HEMI+dSST index from 1925-2015 reveals a pronounced increasing trend over the last 25 years, since the mid-1980s (Fig. 1). The periodogram obtained by means of Fourier spectral analysis supposes an existence of one distinct irregular cycle besides unapparent spectral extremum related to double (22-year) solar cycle (Fig. 2).

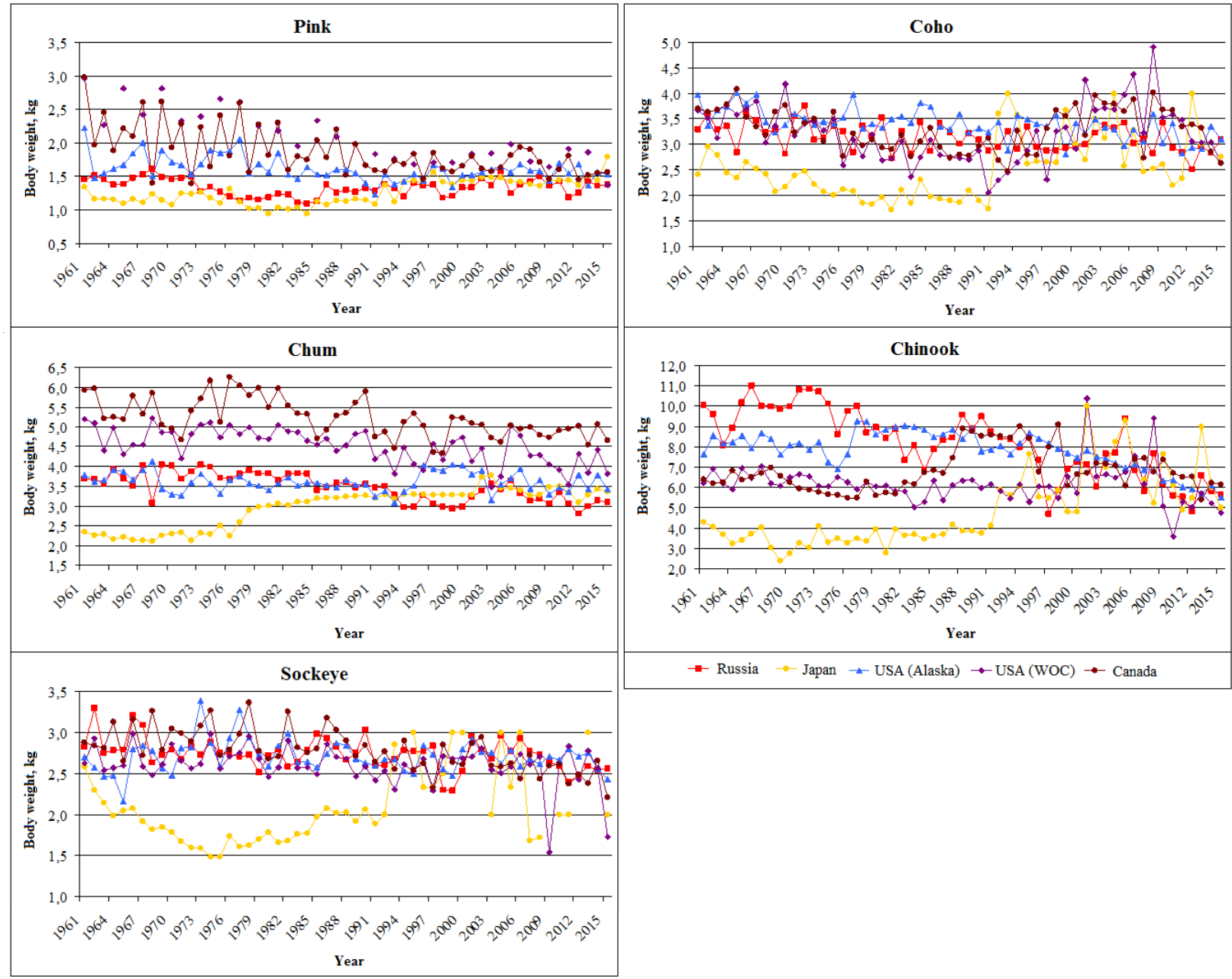

Fig. 3. Pacific salmon body weight dynamics in commercial catches by the NPAFC member countries, 1961-2015.

Most of the salmon body weight data series show a negative trend that reflects an overall tendency towards a lowering of captured salmon body weight (Fig. 3). Data of Japanese fisheries remain an exception due to the significant contribution of the driftnet fishery to the total commercial salmon catch by Japan. This data is excluded from the further analysis.

Russia-Estimated multiple regression coefficients (R) are the highest for chum (0.75) and Chinook (0.86) salmon (Table 2). The regression weight of the temperature anomaly $\left(b_{2}\right)$ is higher for both salmon species: -0.506 for chum and -0.966 for Chinook (Table 3). Regression weight of stock abundance is also relatively high: - 0.281 и 0.348 , accordingly. As for pink, sockeye, and coho salmon, regression coefficients statistically vary between weak and moderate and are rather similar $(R=0.38-0.44)$. Pink salmon body weight demonstrates a negative relationship with stock abundance index $\left(b_{1}=-0.619\right)$ but a positive relationship with N.HEMI+dSST $\left(b_{2}=0.465\right)$. Restricting the analysis by the northern group of pink salmon stocks only (Chukotka, Kamchatka, and mainland Sea of Okhotsk coast), salmon body weight has a moderate relationship with the explanatory variables $(R=0.69)$. While the weight of both variables is close, the regression sign remains opposite: $b_{1}=-0.738$ and $b_{2}=0.713$. It can be supposed that a negative impact of increasing stock abundance on pink salmon growth is compensated by the positive effect of surface layer warming in the North Pacific Ocean (Radchenko et al. 2018). 
Table 2. Results of multiple regression modelling of average Pacific salmon body weight relationship with their commercial catches (1,000 fish) and annual values of the N.HEMI+dSST index, 1961-2015.

\begin{tabular}{lccccccccc}
\hline \multirow{2}{*}{ Regions } & \multicolumn{2}{c}{ Russia } & \multicolumn{2}{c}{ USA (Alaska) } & \multicolumn{2}{c}{ USA (WOC) } & \multicolumn{2}{c}{ Canada } \\
\cline { 2 - 10 } Salmon species & $R$ & $p$ & $R$ & $p$ & $R$ & $p$ & $R$ & $p$ \\
\hline Pink & 0.44 & $<0.01$ & $\mathbf{0 . 6 2}$ & $<0.001$ & $\mathbf{0 . 8 3}$ & $<0.001$ & 0.42 & $<0.01$ \\
Chum & $\mathbf{0 . 7 5}$ & $<0.001$ & 0.20 & 0.348 & $\mathbf{0 . 6 2}$ & $<0.001$ & $\mathbf{0 . 6 4}$ & $<0.001$ \\
Sockeye & 0.38 & $<0.05$ & 0.35 & $<0.05$ & 0.33 & $<0.05$ & $\mathbf{0 . 6 9}$ & $<0.001$ \\
Coho & 0.43 & $<0.01$ & $\mathbf{0 . 5 7}$ & $<0.001$ & 0.13 & 0.656 & 0.36 & $<0.05$ \\
Chinook & $\mathbf{0 . 8 6}$ & $<0.001$ & $\mathbf{0 . 8 1}$ & $<0.001$ & 0.19 & 0.395 & $\mathbf{0 . 5 4}$ & $<0.001$ \\
\hline
\end{tabular}

Remarks: $R$ — coefficient of multiple regression, $p$ —confidence probability

Table 3. Standardized coefficient (beta) estimated to test how well the independent variables (commercial catches and the N.HEMI+dSST index) relate to average Pacific salmon body weight, 1961-2015.

\begin{tabular}{|c|c|c|c|c|c|c|c|c|c|}
\hline \multirow{2}{*}{$\begin{array}{l}\text { Salmon } \\
\text { species }\end{array}$} & \multirow{2}{*}{$\begin{array}{l}\text { Regions: } \\
\text { beta coefficients }\end{array}$} & \multicolumn{2}{|c|}{ Russia } & \multicolumn{2}{|c|}{ USA (Alaska) } & \multicolumn{2}{|c|}{ USA (WOC) } & \multicolumn{2}{|c|}{ Canada } \\
\hline & & beta & $S E$ & beta & $S E$ & beta & $S E$ & beta & $S E$ \\
\hline \multirow[t]{2}{*}{ Pink } & $b_{1}$ (Catch) & -0.619 & 0.178 & -0.796 & 0.180 & -0.129 & 0.112 & -0.121 & 0.135 \\
\hline & $b_{2}(\mathrm{~N} . \mathrm{HEMI}+\mathrm{dSST})$ & 0.465 & 0.178 & 0.247 & 0.180 & -0.834 & 0.112 & -0.444 & 0.135 \\
\hline \multirow[t]{2}{*}{ Chum } & $b_{1}$ (Catch) & -0.281 & 0.147 & 0.344 & 0.236 & -0.249 & 0.188 & -0.255 & 0.109 \\
\hline & $b_{2}(\mathrm{~N} . \mathrm{HEMI}+\mathrm{dSST})$ & -0.506 & 0.147 & -0.302 & 0.236 & -0.404 & 0.188 & -0.648 & 0.109 \\
\hline \multirow[t]{2}{*}{ Sockeye } & $b_{1}$ (Catch) & -0.343 & 0.296 & -0.338 & 0.163 & -0.004 & 0.168 & 0.033 & 0.105 \\
\hline & $b_{2}(\mathrm{~N} . \mathrm{HEMI}+\mathrm{dSST})$ & -0.039 & 0.296 & -0.015 & 0.163 & -0.336 & 0.168 & -0.678 & 0.105 \\
\hline \multirow[t]{2}{*}{ Coho } & $b_{1}($ Catch $)$ & -0.216 & 0.132 & 0.029 & 0.131 & 0.060 & 0.222 & -0.649 & 0.238 \\
\hline & $b_{2}(\mathrm{~N} . H E M I+\mathrm{dSST})$ & -0.310 & 0.132 & -0.587 & 0.131 & 0.168 & 0.222 & -0.491 & 0.238 \\
\hline \multirow[t]{2}{*}{ Chinook } & $b_{1}$ (Catch) & -0.348 & 0.080 & 0.399 & 0.089 & -0.217 & 0.167 & -1.054 & 0.257 \\
\hline & $b_{2}$ (N.HEMI+dSST) & -0.966 & 0.080 & -0.561 & 0.089 & -0.189 & 0.167 & -0.691 & 0.257 \\
\hline
\end{tabular}

Remarks: $b_{1}, b_{2}$ — standardized regression coefficients, $S E$ - standard error

USA (Alaska) - For the Alaskan salmon, estimated multiple regression coefficients $(R)$ are the highest for Chinook (0.81), pink (0.62), and coho salmon (0.57). The regression weight of the temperature anomaly is higher for Chinook and coho: $b_{2}=-0.561$ и -0.587 , accordingly, while stock abundance factor is more significant for pink salmon: $b_{1}=-0.796$. Both factors negatively impact salmon weight growth.

USA (Washington, Oregon, California, or WOC)—Correlations are weak and regression coefficients are very low for two the most important salmon species of this region, coho $(R=0.12)$ and Chinook $(R=0.19)$. It may be related to a high hatchery fish contribution into their total stock abundance. The highest regression coefficients are computed for pink $(R=0.83)$ and chum $(R=0.62)$ salmon. The regression weight of the temperature anomaly was higher for both species: $b_{2}=-0.834$ и -0.404 , correspondingly. For sockeye, the correlation is weak $(R=0.33)$ and the increasing temperature anomaly also increases the impacts for pink and chum salmon, $b_{2}=-0.336$.

Canada - Among the Pacific Rim countries, Canada releases large amounts of fish from hatching facilities and spawning channels. Hatchery fish compose about $70 \%$ of sockeye, and $15-20 \%$ of coho and Chinook populations in the last years. However, both predictors negatively impact weight growth of Canadian salmon. The highest multiple regression coefficients are obtained for sockeye $(R=0.69)$ and chum $(R=0.63)$ salmon. The regression weight of the temperature anomaly was higher than the weight of abundance index for planktivorous salmon species: $b_{2}=-0.444$ for pink, -0.648 for chum, and -0.678 for sockeye. For "predatory" salmon species, the 
regression weight of stock abundance was notably higher: $b_{1}=-0.649, b_{2}=-0.491$ for coho and $b_{1}=-1.054, b_{2}=-$ 0.691 for Chinook. In $\sim 85 \%$ of cases, a complex interrelation is observed between average body weight and "stock abundance + global temperature anomaly" indices. The correlation coefficient $R$ is $<0.3$ in $15 \%,>0.3 \leq 0.6$ in $45 \%$, and $>0.6$ in $40 \%$ of the cases examined.

In conclusion, the N.HEMI+dSST index is the most significant factor in about $70 \%$ of the multiple regressions under consideration. A negative impact of the increasing temperature anomaly is more significant in the southernmost of the studied regions, in the USA (WOC) and Canada. This is quite understandable since the negative effect of temperature increases on Pacific salmon becomes evident primarily near the southern borders of their areas.

For most of the Pacific salmon stocks, there are different changing long-term trends in Pacific salmon body weight dynamics and no universal relationships are evident; for example, pink salmon body weight in Russian commercial catches had a negative trend till the mid-1980s, which was later replaced by a considerably unstable positive trend. These short-term trends are determined by multivariable interactions of environmental factors and their variable influence on salmon growth at different life stages. The periodicity of a trend breaks should be taken into account when considering regulations of Pacific salmon size and weight dynamics over a long period of time.

\section{REFERENCES}

Bugaev, A.V. 2017. Evaluation of contributions of stock abundance and global temperature anomaly to mean body weight of pacific salmons in the North Pacific basin // Izv. TINRO. 191: 3-33. (In Russian)

Radchenko, V.I., R.J. Beamish, W.R. Heard, and O.S. Temnykh. 2018. Ocean Ecology of Pink Salmon. In: Beamish, R.J. (Editors). The ocean ecology of Pacific salmon and trout. American Fisheries Society, 1,090 pp. ISBN-13: 978-1-934874-45-5 